\title{
Novel Peritoneal Dialysis Solutions - What Are the Clinical Implications?
}

\author{
Achim Jörres \\ Department of Nephrology and Medical Intensive Care, Charité University Hospital, Campus Virchow-Klinikum, \\ Berlin, Germany
}

\section{Key Words}

Peritoneal dialysis - Glucose degradation products · Icodextrin

\begin{abstract}
Novel low-glucose degradation products (GDP) peritoneal dialysis (PD) fluids have an improved biocompatibility profile as compared to standard fluids. Clinical studies suggest that their use may be associated with favorable clinical outcomes; however, large prospective randomized studies addressing clinical endpoints such as patient and technique survival are presently lacking. Nevertheless, as their only disadvantage is their cost, they are already being used as the standard treatment by many adult PD centers. This policy is also in line with the latest recommendations from the European Pediatric Dialysis Working Group which advises that conventional, single-chamber PD solutions should be replaced by PD solutions with reduced GDP content. The use of icodextrin, the glucose polymer PD solution, is recommended for patients with high or high-average peritoneal transport and/or ultrafiltration problems who otherwise would resort to hypertonic (3.86\% glucose) exchanges. Copyright $\odot 2012$ S. Karger AG, Basel
\end{abstract}

\section{Introduction}

Peritoneal dialysis $(\mathrm{PD})$ requires the infusion of peritoneal dialysis fluids (PDF) into the peritoneal cavity in order to enable ultrafiltration (UF) and solute transport across the peritoneal membrane. While the 'old' dialysis fluids that have been used over the past decades did indeed fulfill this purpose, it has become apparent, however, that long-term PD in many patients results in structural and functional alterations of the peritoneum that eventually jeopardize its function as the dialysis membrane. These alterations include loss of mesothelial cells, thickening of the submesothelial compact zone, and changes of peritoneal vascularization [1].

On the cellular level, chronic PD is associated with the phenomenon of epithelial-to-mesenchymal transformation as well as premature aging and senescence of mesothelial cells [2-4]. Evidence accumulated over the past years indicates that the unphysiological composition of classic PDF may constitute a major culprit in this scenario. Their acidic $\mathrm{pH}$ (as low as $\mathrm{pH}$ 5.2), hyperosmolality (as high as $511 \mathrm{mOs} / \mathrm{kg}$ ), and enormous glucose content (up to $4.25 \mathrm{~g} / \mathrm{dl}$ ) were demonstrated to interfere with a multitude of essential functions of both peritoneal immune cells as well as resident cell populations such as mesothelial cells and fibroblasts $[5,6]$. In addition, toxic components were identified that are generated from glucose

Department of Nephrology and Medical Intensive Care, Charité University Hospital

Campus Virchow-Klinikum, Augustenburger Platz 1

DE-13353 Berlin (Germany)

Tel. +49 30450553 423, E-Mail achim.joerres@ charite.de 
Table 1. Characteristics of PDF (adapted from [58])

\begin{tabular}{|c|c|c|c|c|c|c|c|c|}
\hline & \multicolumn{3}{|c|}{ Conventional PDF } & \multicolumn{4}{|c|}{ Low-GDP PDF } & \multirow{2}{*}{$\begin{array}{l}\text { Icodextrin } \\
\text { Extraneal } \\
\text { (7.5\% icodextrin) }\end{array}$} \\
\hline & $\begin{array}{l}\text { CAPD } \\
2 / 3 / 4\end{array}$ & $\begin{array}{l}\text { Dianeal } \\
\text { PD 1, PD2, PD } 4\end{array}$ & $\begin{array}{l}\text { Gambrosol } \\
10 / 40\end{array}$ & BicaVera & Balance & $\begin{array}{l}\text { Gambrosol } \\
\text { Trio 10/40 }\end{array}$ & $\begin{array}{l}\text { Physioneal } \\
35 / 40\end{array}$ & \\
\hline Sodium, mmol/l & 134 & 132 & 132 & 132 & 134 & 132 & 132 & 132 \\
\hline Chloride, $\mathrm{mmol} / \mathrm{l}$ & 102.5 & $102 / 96 / 95$ & $96 / 95$ & 104.5 & 100.5 & 96 & $101 / 95$ & 96 \\
\hline Calcium, mmol/l & $1.25 / 1.75$ & $1.75 / 1.75 / 1.25$ & $1.75 / 1.35$ & 1.75 & $1.25 / 1.75$ & $1.75 / 1.35$ & $1.75 / 1.25$ & 1.75 \\
\hline Magnesium, mmol/l & 0.5 & $0.75 / 0.75 / 0.25$ & 0.25 & 0.5 & 0.5 & 0.25 & 0.25 & 0.25 \\
\hline Glucose, $\%$ & $1.5 / 2.3 / 4.25$ & $1.36 / 2.27 / 3.86$ & $1.5 / 2.5 / 4.0$ & $1.5 / 2.3 / 4.25$ & $1.5 / 2.3 / 4.25$ & $1.5 / 2.5 / 3.9$ & $1.36 / 2.27 / 3.86$ & 0 \\
\hline Osmolarity, mOs/l & $356-509$ & $344-486$ & $353-492$ & $358-511$ & $358-511$ & $356-483$ & $344-484$ & 284 \\
\hline Lactate, $\mathrm{mmol} / \mathrm{l}$ & 35 & $35 / 40 / 40$ & 40 & 0 & 35 & 40 & $10 / 15$ & 40 \\
\hline Bicarbonate, $\mathrm{mmol} / \mathrm{l}$ & 0 & 0 & 0 & 34 & 0 & 0 & $25 / 25$ & 0 \\
\hline $\mathrm{pH}$ & 5.5 & 5.5 & 5.5 & 7.4 & 7 & $5.5-6.5$ & 7.4 & 5.5 \\
\hline Formaldehyde, mmol/l & $5.4 \pm 0.4$ & $6.8 \pm 0.2$ & $6.4 \pm 0.5$ & $<3.3$ & $<3.3$ & $<3.3$ & $3.4 \pm 0$ & $3.6 \pm 0.7$ \\
\hline 3-DG, mmol/l & $142 \pm 0.8$ & $167 \pm 0.3$ & $175 \pm 4$ & $16.3 \pm 0.2$ & $17.6 \pm 0.3$ & $20.2 \pm 2.4$ & $93.3 \pm 5.0$ & $7.5 \pm 0.4$ \\
\hline 3,4-DGE, $\mathrm{mmol} / \mathrm{l}$ & $16.2 \pm 0.8$ & $11.3 \pm 0.5$ & $13.1 \pm 1.1$ & $<2.4$ & $<2.4$ & $<2.4$ & $14.3 \pm 2.5$ & $<2.4$ \\
\hline
\end{tabular}

DG = Deoxyglucosone; 3,4-DGE = di-deoxyglucosone-3-ene.

during both manufacture (heat sterilization) and storage: glucose degradation products (GDP), a conglomerate of aldehydes, carbonyls, and their derivatives that in turn may promote the formation of advanced glycation endproducts (AGE) $[7,8]$.

Conventional PDF were evaluated in numerous in vitro and animal studies that have unequivocally demonstrated their (acute and chronic) toxicity towards peritoneal cells and structures [9-12]. Consequently, these findings have stimulated a search for novel, more biocompatible PDF. As a result, new generations of PDF were developed that either replace glucose as the osmotic agent or, alternatively, apply multichamber bag systems that separate highly concentrated glucose at low $\mathrm{pH}$ from buffers and electrolytes, thus resulting in markedly reduced GDP content (table 1). In the meantime, these novel PDF have been introduced into clinical practice in many countries in Europe, Asia, and the Americas. While little doubt remains as to their improved in vitro biocompatibility profile [13-15], their actual impact on clinical outcomes is less clear to date. The present article focuses on recent findings from clinical studies with novel PDF and their potential clinical implications.

\section{Novel PD Solutions in Clinical Studies}

\section{Effect of Low-GDP Fluids on Markers of}

Biocompatibility

Initial clinical studies with novel low-GDP fluids have primarily investigated surrogate markers for biocompat- ibility, but were underpowered for hard clinical endpoints such as patient or technique survival. The typical biomarker evaluated in multiple studies has been cancer antigen-125 (CA-125) in peritoneal effluent, a glycoprotein that is constitutively produced by mesothelial cells and therefore often viewed as a putative marker of mesothelial cell mass and integrity. While the studies to date uniformly report an increase of CA-125 during use of low-GDP fluids [16], the potential clinical relevance of this finding remains controversial as CA-125 might also be derived from damaged cells and/or generated as a consequence of subclinical chronic inflammation [17]. Some studies have also investigated cytokines such as IL-6 or extracellular matrix components such as hyaluronic acid, and have generally reported favorable results that support the notion of improved biocompatibility with low-GDP fluids [18-20]. A few studies have also examined the effect of low-GDP fluids on circulating GDP and AGE such as carboxymethyllysine or imidazolone, which were found to be lower as compared to patients treated with conventional PDF $[21,22]$. However, the potential implications of reducing the level of circulating AGE in the clinical context of PD mostly remain to be established as correlations with relevant clinical endpoints are presently lacking. The most recent study included 152 incident patients from seven Korean centers in a multicenter, open-labeled, randomized controlled trial who were followed for 1 year [23]. The primary outcome variable, a composite score derived from serum levels of soluble intercellular adhesion molecule-1, soluble vascular cellular adhesion molecule-1, and high-sen- 
sitivity C-reactive protein, was found to be significantly lower in patients treated with Balance low-GDP fluid, suggesting less endothelial dysfunction. However, there was no difference between the groups regarding peritoneal transport characteristics, residual renal function (RRF), nutritional parameters, peritonitis incidence, or technique survival.

\section{Effect of Low-GDP Fluids on Patient and Technique Survival}

Two studies to date have attempted to clarify if the use of novel low-GDP fluids is associated with improved patient survival. In a prospective, longitudinal observational cohort, Lee et al. [24] followed 1,909 incident patients for up to 4 years. Analysis using a proportional hazards model including age, diabetes, and center experience indicated that low-GDP fluid independently reduced the relative risk of death $(\mathrm{RR}=0.613$; CI: $0.50-0.74 ; \mathrm{p}<$ 0.00001). Better technique survival with the low-GDP fluid was significant $(\mathrm{p}=0.049)$ in univariate but not multivariate analysis. Similarly, Han et al. [25] studied 2,163 incident patients from 54 centers in Korea for up to 4 years, 542 of whom initiated PD with Physioneal lowGDP fluid. Propensity score matching resulted in 542 matched pairs of patients. In the matched cohort, there were no significant differences in age, diabetes, cardiovascular comorbidity, icodextrin use, or center experience; however, Physioneal use was associated with a reduced risk of death (HR: 0.70 ; 95\% CI: $0.50-0.98 ; \mathrm{p}=$ $0.04)$.

\section{Effect of Low-GDP Fluids on Peritonitis Incidence}

Most data on the potential impact of novel low-GDP fluid originate either from observational studies or from prospective randomized studies that used peritonitis incidence only as a secondary endpoint. The large Korean registry $[24,26]$ did not find a difference in peritonitis incidence or peritonitis-free survival. In contrast, Ahmad et al. [27] analyzed data from 121 episodes of peritonitis from patients either treated with Physioneal or conventional PDF. From these, 107 episodes occurred in patients using standard PDF and only 14 episodes in patients using Physioneal, corresponding to a significantly lower peritonitis rate ( 1 per 52.5 patient-months compared to 1 per 26.9 patient-months with standard PDF, $\mathrm{p}=0.0179$ ). A reduction in peritonitis incidence was also observed in a prospective observational study with BicaVera bicarbonate-buffered low-GDP fluid (1 episode per 35.5 months compared to 1 per 20.4 months with standard PDF; $\mathrm{p}=0.017)$ [28].

Clinical Implications of Novel PD Solutions

\section{Effect of Low-GDP Fluids on Peritoneal UF}

Data on the potential impact of low-GDP fluids on peritoneal UF is highly controversial and mostly derived from studies using peritoneal UF as a secondary outcome. Published results range from better [29] to unchanged [30] or even impaired [31] short-term UF with the identical low-GDP fluid. In a recent cross-over study, Pajek et al. [32] investigated UF and other peritoneal membrane indices in 26 stable, prevalent PD patients who were treated for 3 months with either Physioneal or conventional PDF and then switched to the other treatment. The mean daily peritoneal UF with conventional PDF was $1,324 \pm 602 \mathrm{ml}$ and $881 \pm 633 \mathrm{ml}$ with Physioneal $(\mathrm{p}<0.001)$; however, the decrease in peritoneal UF with Physioneal was reversible. While there were no differences in other peritoneal membrane indices (D/P creatinine, D/D0 glucose, UF during PET, weekly creatinine clearance, weekly urea Kt/V), the calculated peritoneal fluid absorption rate was significantly higher with Physioneal, which likely explains the reduced peritoneal UF. In contrast, a prospective randomized study over 12 months in 104 patients comparing Balance low-GDP fluid and standard PDF reported both significantly higher peritoneal UF and higher Kt/V urea values with Balance [33].

\section{Effect of Low-GDP Fluids on RRF}

The preservation of RRF is generally recognized as an important predictor of patient survival in chronic dialysis. It has been hypothesized that the use of low-GDP fluids might result in better RRF preservation through either direct (e.g. reduced systemic GDP levels and thus reduced tubular toxicity) or indirect mechanisms (e.g. reduced formation of AGE). Indeed, the Euro-Balance Study, a multicenter randomized study with a crossover design comparing Balance low-GDP fluid with conventional PDF in 86 patients over $2 \times 12$ weeks, reported higher urea and creatinine clearances as well as higher urine volume in patients exposed to Balance [18]. Since then, several prospective randomized studies have attempted to further corroborate these findings; however, the results have been controversial. Kim et al. [34] compared Balance and standard PDF in a multicenter study over 12 months in 91 incident continuous ambulatory peritoneal dialysis (CAPD) patients and found a better conservation of RRF in patients treated with Balance. The effect was most pronounced in patients with residual GFR $\geq 2 \mathrm{ml} / \mathrm{min} / 1.73 \mathrm{~m}^{2}$. Haag-Weber et al. [35] randomized 80 patients with a GFR $\geq 3 \mathrm{ml} / \mathrm{min} / 1.73 \mathrm{~m}^{2}$ to treatment with Gambrosol Trio low-GDP fluid or conventional PDF 
for 18 months. They found a significantly smaller monthly RRF change with Gambrosol Trio: $-1.5 \%$ (95\% CI: -3.07 to $+0.03 \%$ ) compared to $-4.3 \%$ (95\% CI: -6.8 to $-2.06 \%)$ with standard PDF ( $\mathrm{p}=0.0437)$. Moreover, urine volume declined more slowly with low-GDP fluid compared to standard fluid ( 12 vs. $38 \mathrm{ml} / \mathrm{month} ; \mathrm{p}=0.0437$ vs. lowGDP fluid). Finally, Fan et al. [30] randomized 118 incident patients (47 CAPD/71 APD) to receive either biocompatible or standard PDF and found no difference in outcomes after 12 months. In this study, however, different test fluids were used (mostly Physioneal and Dianeal, with a few patients receiving Balance low-GDP fluid). The largest prospective randomized controlled trial targeting RRF with novel PDF, the balANZ study [36], has been completed in the meantime and the results are expected soon. In this study, 185 patients were randomized to treatment with either Balance low-GDP fluid or conventional PDF with a follow-up of 2 years.

\section{Effect of Icodextrin (Extraneal) on Clinical Outcomes}

Strictly speaking, icodextrin, the glucose polymer solution, is not a 'novel' PDF as the first clinical studies were performed in the early 1990s and market introduction throughout Europe followed shortly thereafter. However, in some parts of the world, including North America, its availability for clinical use does not date back as long. In the USA, FDA approval was granted in December 2002 and its use has been gradually increasing since.

Icodextrin is a water-soluble glucose polymer isolated by fractionation of hydrolyzed corn starch. Unlike glucose and other small molecules that are absorbed from the peritoneal cavity primarily by diffusion across the capillaries within the peritoneal membrane, icodextrin is not easily absorbed through the small pores due to its high molecular weight - the majority of icodextrin polymers have a molecular weight between 1,638 and 45,000 $\mathrm{Da}$ [37]. As a consequence, icodextrin absorption primarily occurs through convective fluid movement and is much slower than the reabsorption of glucose, thus maintaining an UF gradient for much longer time. Despite the fact that between 20 and $40 \%$ of the infused icodextrin is absorbed from the peritoneum during a long dwell, it still results in a sustained net UF. Therefore, it is not surprising that when comparing icodextrin with glucose, the greatest relative benefit is seen in patients with high transport status $[38,39]$. This seems particularly true in patients with diabetes as suggested by a recent randomized controlled trail in 59 prevalent patients followed over 12 months [40]. However, a recent randomized, doubleblind study from China in 201 prevalent CAPD patients compared the effect of either $7.5 \%$ icodextrin or $2.5 \%$ glucose solution for 4 weeks and reported improved small solute clearance and better UF with icodextrin. Interestingly, the increase in UF occurred across all PET transport groups, indicating that icodextrin can also be used in patients with fluid overload who have low or low-average transport status [41].

Initially, icodextrin was successfully used as a salvage therapy for patients with UF failure in whom it extended technique survival $[42,43]$. However, more recent study data suggest that icodextrin not only increases UF, but may actually impact the overall fluid status of patients. Two randomized controlled trials indicated that use of icodextrin was associated with a significant reduction of extracellular fluid volume $[44,45]$. Neither study, however, demonstrated a benefit of icodextrin use on blood pressure. Icodextrin use might also be associated with more stable membrane function as compared to patients using only glucose as was suggested by a secondary analysis of data from the European Automated Peritoneal Dialysis Outcome Study, an observational cohort of functionally anuric patients [46]. On the other hand, in one study a significant reduction in urine volume occurred, a warning sign that excess UF with icodextrin might have negative consequences on RRF [44].

In contrast to the low-GDP fluids discussed above, icodextrin is manufactured in single-chambered bags and still maintains an acidic $\mathrm{pH}$ which might be one of the reasons that its in vitro biocompatibility profile is controversial. Some in vitro data suggest that its effects on peritoneal cells might be similarly destructive as with high glucose concentrations [47]. It may also lead to an increase of circulating AGE [48]. On the other hand, it has also been suggested that the use of icodextrin might be beneficial beyond acute biocompatibility as it can reduce the overall use of glucose in PD and thus, at least theoretically, the glucose-associated side effects [49]. Among other things, it may improve diabetic control, blunt the hyperinsulinemic response and reduce the delayed gastric emptying seen with glucose containing solutions [50,51]. An improvement of lipid profiles was also reported [52], but remains to be confirmed in larger clinical studies.

Potential clinical side effects of icodextrin must also be mentioned. In some patients, use of icodextrin may lead to allergic reaction, mostly manifesting itself as a skin rash [53]. It may also induce sterile peritonitis, which in many cases could be attributed to contamination with peptidoglycan, the bacterial product [54]. Despite the subsequent adherence to peptidoglycan levels $<7.4 \mu \mathrm{g} / 1$ in icodextrin, PDF-associated cases of sterile peritonitis 
still occur [55]. While icodextrin-induced sterile peritonitis often results in a relatively mild clinical course that might suggest less severe peritoneal injury, this assumption is not necessarily true. In a series of 4 cases with relapsing icodextrin-associated sterile peritonitis, all patients had to be switched to hemodialysis within 8 months because of UF failure [56].

\section{Summary}

There is compelling evidence that novel low-GDP dialysis fluids have a markedly improved biocompatibility profile as compared to standard fluids. Numerous clinical studies suggest that this may also translate into favorable clinical outcomes; however, it is true that large prospective randomized studies that address the most relevant clinical endpoints such as patient and technique survival are presently lacking. On the other hand, there is little suspicion that the novel low-GDP dialysis may confer any disadvantages (other than increased costs). On balance, many PD centers across Europe have therefore already decided that the potential benefits clearly outweigh the increases in costs and have made low-GDP fluids their standard treatment, at least for new patients. This development is already limiting the chances for further multicenter studies comparing low-GDP fluids to standard PDF, which biocompatibility skeptics demand before novel fluids can be considered the standard of care
[57]. In contrast, pediatric nephrologists are less reserved: the European Pediatric Dialysis Working Group has recently published recommendations that conventional, single-chamber PD solutions should be replaced by PD solutions with reduced GDP content [58]. According to the International Pediatric PD Network Registry (www. pedpd.org), $60 \%$ of the PD children in Europe were treated with reduced-GDP multichamber PD solutions in 2010.

The domain for clinical use of icodextrin is the patient with high or high-average peritoneal transport and/or UF problems and has, as such, found entry into current guidelines. For example, the 2010 guidelines of the British Renal Association (www.renal.org/guidelines) recommend that dialysis regimens resulting in fluid reabsorption should be avoided and that patients with high or high-average solute transport (those at the greatest risk for this problem) should be considered for APD and icodextrin. Moreover, it is recommended that dialysis regimens resulting in routine utilization of hypertonic (3.86\%) glucose exchanges should be avoided and that this should be achieved by using icodextrin or diuretics where appropriate. However, the latter recommendation should not lead to the indiscriminate use of icodextrin in every patient simply with the concept of 'glucose sparing' as this is clearly not supported by available data. Caution needs to be taken against potential side effects such as dehydration that might threaten RRF, 'sterile' peritonitis, and allergenic reactions.

\section{References}

$>1$ Williams JD, Craig KJ, Topley N, Von Ruhland C, Fallon M, Newman GR, Mackenzie RK, Williams GT: Morphologic changes in the peritoneal membrane of patients with renal disease. J Am Soc Nephrol 2002;13:470479.

-2 Witowski J, Ksiazek K, Jörres A: New insights into the biology of peritoneal mesothelial cells: the roles of epithelial-to-mesenchymal transition and cellular senescence. Nephron Exp Nephrol 2008;108:e69-e73.

3 Witowski J, Jörres A: Peritoneal Dialysis: A Biological Membrane with a Nonbiological Fluid. Contrib Nephrol. Basel, Karger, 2009, vol 163, pp 27-34.

4 Witowski J, Ksiazek K, Jörres A: Glucose-induced mesothelial cell senescence and peritoneal neoangiogenesis and fibrosis. Perit Dial Int 2008;28(suppl 5):S34-S37.

$\checkmark 5$ Jörres A, Gahl GM, Frei U: Peritoneal dialysis fluid biocompatibility: does it really matter? Kidney Int Suppl 1994;48:S79-S86.
6 Jörres A: Effect of peritoneal dialysis on peritoneal cell biology: peritoneal fibroblasts. Perit Dial Int 1999;19(suppl 2):S348-S352.

7 Nilsson Thorell CB, Muscalu N, Andren AH, Kjellstrand PT, Wieslander AP: Heat sterilization of fluids for peritoneal dialysis gives rise to aldehydes. Perit Dial Int 1993;13:208213.

$>8$ Lamb EJ, Cattell WR, Dawnay AB: In vitro formation of advanced glycation end products in peritoneal dialysis fluid. Kidney Int 1995;47:1768-1774.

9 Witowski J, Jörres A: Glucose degradation products: relationship with cell damage. Perit Dial Int 2000;20(suppl 2):S31-S36.

10 Witowski J, Wisniewska J, Korybalska K Bender TO, Breborowicz A, Gahl GM, Frei U, Passlick-Deetjen J, Jörres A: Prolonged exposure to glucose degradation products impairs viability and function of human peritoneal mesothelial cells. J Am Soc Nephrol 2001;12:2434-2441.
11 Jörres A: Glucose degradation products in peritoneal dialysis: from bench to bedside. Kidney Blood Press Res 2003;26:113-117.

12 Witowski J, Bender TO, Wisniewska-Elnur J, Ksiazek K, Passlick-Deetjen J, Breborowicz A, Jörres A: Mesothelial toxicity of peritoneal dialysis fluids is related primarily to glucose degradation products, not to glucose per se. Perit Dial Int 2003;23:381-390.

13 Topley N, Kaur D, Petersen MM, Jörres A, Williams JD, Faict D, Holmes CJ: In vitro effects of bicarbonate and bicarbonate-lactate buffered peritoneal dialysis solutions on mesothelial and neutrophil function. J Am Soc Nephrol 1996;7:218-224.

14 Topley N, Kaur D, Petersen MM, Jörres A, Passlick Deetjen J, Coles GA, Williams JD: Biocompatibility of bicarbonate buffered peritoneal dialysis fluids: influence on mesothelial cell and neutrophil function. Kidney Int 1996;49:1447-1456. 
15 Jörres A, Bender TO, Finn A, Witowski J, Fröhlich S, Gahl GM, Frei U, Keck H, Passlick-Deetjen J: Biocompatibility and buffers: effect of bicarbonate-buffered peritoneal dialysis fluids on peritoneal cell function. Kidney Int 1998;54:2184-2193.

16 Witowski J, Jörres A: Effects of peritoneal dialysis solutions on the peritoneal membrane: clinical consequences. Perit Dial Int 2005; 25(suppl 3):S31-S34.

17 Topley N, Michael D, Bowen T: CA125: Holy Grail or a poisoned chalice. Nephron Clin Pract 2005; 100:c52-c54.

-18 Williams JD, Topley N, Craig KJ, Mackenzie RK, Pischetsrieder M, Lage C, PasslickDeetjen J: The Euro-Balance Trial: the effect of a new biocompatible peritoneal dialysis fluid (balance) on the peritoneal membrane. Kidney Int 2004;66:408-418.

$\checkmark 19$ Cooker LA, Luneburg P, Faict D, Choo C, Holmes CJ: Reduced glucose degradation products in bicarbonate/lactate-buffered peritoneal dialysis solutions produced in two-chambered bags. Perit Dial Int 1997;17: 373-378.

-20 Szeto CC, Chow KM, Lam CW, Leung CB, Kwan BC, Chung KY, Law MC, Li PK: Clinical biocompatibility of a neutral peritoneal dialysis solution with minimal glucose-degradation products - a 1-year randomized control trial. Nephrol Dial Transplant 2007; 22:552-559.

-21 Zeier M, Schwenger V, Deppisch R, Haug U, Weigel K, Bahner U, Wanner C, Schneider H, Henle T, Ritz E: Glucose degradation products in PD fluids: do they disappear from the peritoneal cavity and enter the systemic circulation? Kidney Int 2003;63:298-305.

-22 Schmitt CP, von Heyl D, Rieger S, Arbeiter K, Bonzel KE, Fischbach M, Misselwitz J, Pieper AK, Schaefer F: Reduced systemic advanced glycation end products in children receiving peritoneal dialysis with low glucose degradation product content. Nephrol Dial Transplant 2007;22:2038-2044.

23 Park SH, Do JY, Kim YH, Lee HY, Kim BS, Shin SK, Kim HC, Chang YK, Yang JO, Chung HC, Kim CD, Lee WK, Kim JY, Kim YL: Effects of neutral $\mathrm{pH}$ and low-glucose degradation product-containing peritoneal dialysis fluid on systemic markers of inflammation and endothelial dysfunction: a randomized controlled 1-year follow-up study. Nephrol Dial Transplant 2011, E-pub ahead of print.

24 Lee HY, Choi HY, Park HC, Seo BJ, Do JY, Yun SR, Song HY, Kim YH, Kim YL, Kim DJ, Kim YS, Kim MJ, Shin SK: Changing prescribing practice in CAPD patients in Korea: increased utilization of low GDP solutions improves patient outcome. Nephrol Dial Transplant 2006;21:2893-2899.

25 Han SH, Ahn SV, Yun JY, Tranaeus A, Han DS: Mortality and technique failure in peritoneal dialysis patients using advanced peritoneal dialysis solutions. Am J Kidney Dis 2009;54:711-720.
26 Lee HY, Park HC, Seo BJ, Do JY, Yun SR, Song HY, Kim YH, Kim YL, Kim DJ, Kim YS, Ahn C, Kim MJ, Shin SK: Superior patient survival for continuous ambulatory peritoneal dialysis patients treated with a peritoneal dialysis fluid with neutral $\mathrm{pH}$ and low glucose degradation product concentration (Balance). Perit Dial Int 2005;25:248-255.

27 Ahmad S, Sehmi JS, Ahmad-Zakhi KH, Clemenger M, Levy JB, Brown EA: Impact of new dialysis solutions on peritonitis rates. Kidney Int Suppl 2006;103:S63-S66.

28 Montenegro J, Saracho R, Gallardo I, Martinez I, Munoz R, Quintanilla N: Use of pure bicarbonate-buffered peritoneal dialysis fluid reduces the incidence of CAPD peritonitis. Nephrol Dial Transplant 2007;22:17031708 .

29 Tranaeus A: A long-term study of a bicarbonate/lactate-based peritoneal dialysis solution - clinical benefits. The Bicarbonate/ Lactate Study Group. Perit Dial Int 2000;20: 516-523.

30 Fan SL, Pile T, Punzalan S, Raftery MJ, Yaqoob MM: Randomized controlled study of biocompatible peritoneal dialysis solutions: effect on residual renal function. Kidney Int 2008;73:200-206.

31 Fang W, Mullan R, Shah H, Mujais S, Bargman JM, Oreopoulos DG: Comparison between bicarbonate/lactate and standard lactate dialysis solution in peritoneal transport and ultrafiltration: a prospective, crossover single-dwell study. Perit Dial Int 2008;28: $35-43$

32 Pajek J, Kveder R, Bren A, Gucek A, Bucar M, Skoberne A, Waniewski J, Lindholm B Short-term effects of bicarbonate/lactatebuffered and conventional lactate-buffered dialysis solutions on peritoneal ultrafiltration: a comparative crossover study. Nephrol Dial Transplant 2009;24:1617-1625.

33 Choi HY, Kim DK, Lee TH, Moon SJ, Han SH, Lee JE, Kim BS, Park HC, Choi KH, Ha SK, Han DS, Lee HY: The clinical usefulness of peritoneal dialysis fluids with neutral $\mathrm{pH}$ and low glucose degradation product concentration: an open randomized prospective trial. Perit Dial Int 2008;28:174-182.

34 Kim S, Oh J, Kim S, Chung W, Ahn C, Kim SG, Oh KH: Benefits of biocompatible PD fluid for preservation of residual renal function in incident CAPD patients: a 1-year study. Nephrol Dial Transplant 2009;24: 2899-2908.

35 Haag-Weber M, Kramer R, Haake R, Islam MS, Prischl F, Haug U, Nabut JL, Deppisch R, DIUREST Study Group: Low-GDP fluid (Gambrosol Trio) attenuates decline of residual renal function in PD patients: a prospective randomized study. Nephrol Dial Transplant 2010;25:2288-2296.
36 Johnson DW, Clarke M, Wilson V, Woods F, Brown FG: Rationale and design of the balANZ trial: a randomised controlled trial of low GDP, neutral $\mathrm{pH}$ versus standard peritoneal dialysis solution for the preservation of residual renal function. BMC Nephrol 2010; 11:25.

-37 Garcia-Lopez E, Lindholm B: Icodextrin metabolites in peritoneal dialysis. Perit Dial Int 2009;29:370-376.

- 38 Wolfson M, Piraino B, Hamburger RJ, Morton AR: A randomized controlled trial to evaluate the efficacy and safety of icodextrin in peritoneal dialysis. Am J Kidney Dis 2002; 40:1055-1065.

-39 Finkelstein F, Healy H, Abu-Alfa A, Ahmad S, Brown F, Gehr T, Nash K, Sorkin M, Mujais S: Superiority of icodextrin compared with $4.25 \%$ dextrose for peritoneal ultrafiltration. J Am Soc Nephrol 2005;16:546554.

-40 Paniagua R, Ventura MD, Avila-Diaz M, Cisneros A, Vicente-Martinez M, Furlong MD, Garcia-Gonzalez Z, Villanueva D, Orihuela O, Prado-Uribe MD, Alcantara G, Amato D: Icodextrin improves metabolic and fluid management in high and high-average transport diabetic patients. Perit Dial Int 2009;29:422-432.

41 Lin A, Qian J, Li X, Yu X, Liu W, Sun Y, Chen $\mathrm{N}$, Mei C: Randomized controlled trial of icodextrin versus glucose containing peritoneal dialysis fluid. Clin J Am Soc Nephrol 2009;4:1799-1804.

42 Wilkie ME, Plant MJ, Edwards L, Brown CB: Icodextrin $7.5 \%$ dialysate solution (glucose polymer) in patients with ultrafiltration failure: extension of CAPD technique survival. Perit Dial Int 1997;17:84-87.

43 Johnson DW, Arndt M, O'Shea A, Watt R, Hamilton J, Vincent K: Icodextrin as salvage therapy in peritoneal dialysis patients with refractory fluid overload. BMC Nephrol 2001;2:2.

44 Konings CJ, Kooman JP, Schonck M, Gladziwa U, Wirtz J, van den Wall Bake AW, Gerlag PG, Hoorntje SJ, Wolters J, Van Der Sande FM, Leunissen KM: Effect of icodextrin on volume status, blood pressure and echocardiographic parameters: a randomized study. Kidney Int 2003;63:1556-1563.

45 Davies SJ, Woodrow G, Donovan K, Plum J, Williams P, Johansson AC, Bosselmann HP, Heimburger O, Simonsen O, Davenport A, Tranaeus A, Divino Filho JC: Icodextrin improves the fluid status of peritoneal dialysis patients: results of a double-blind randomized controlled trial. J Am Soc Nephrol 2003; 14:2338-2344.

-46 Davies SJ, Brown EA, Frandsen NE, Rodrigues AS, Rodriguez-Carmona A, Vychytil A, MacNamara E, Ekstrand A, Tranaeus A, Filho JC: Longitudinal membrane function in functionally anuric patients treated with APD: data from EAPOS on the effects of glucose and icodextrin prescription. Kidney Int 2005;67:1609-1615. 
-47 Bender TO, Witowski J, Ksiazek K, Jörres A: Comparison of icodextrin- and glucosebased peritoneal dialysis fluids in their acute and chronic effects on human peritoneal mesothelial cells. Int J Artif Organs 2007;30: 1075-1082.

48 Konings CJ, Schalkwijk CG, Van Der Sande FM, Leunissen KM, Kooman JP: Influence of icodextrin on plasma and dialysate levels of $\mathrm{N}$ (epsilon)-(carboxymethyl)lysine and N(epsilon)-(carboxyethyl)lysine. Perit Dial Int 2005;25:591-595.

49 Holmes CJ, Shockley TR: Strategies to reduce glucose exposure in peritoneal dialysis patients. Perit Dial Int 2000;20(suppl 2):S37-S41.

50 Marshall J, Jennings P, Scott A, Fluck RJ, McIntyre CW: Glycemic control in diabetic CAPD patients assessed by continuous glucose monitoring system (CGMS). Kidney Int 2003;64:1480-1486.
51 Van V, Schoonjans RS, Struijk DG, Verbanck JJ, Vanholder RC, Van B, Lefebvre RA, De V, Lameire NH: Influence of dialysate on gastric emptying time in peritoneal dialysis patients. Perit Dial Int 2002;22:32-38.

52 Bredie SJ, Bosch FH, Demacker PN, Stalenhoef AF, van Leusen R: Effects of peritoneal dialysis with an overnight icodextrin dwell on parameters of glucose and lipid metabolism. Perit Dial Int 2001;21:275-281.

53 Goldsmith D, Jayawardene S, Sabharwal N, Cooney K: Allergic reactions to the polymeric glucose-based peritoneal dialysis fluid icodextrin in patients with renal failure. Lancet 2000;355:897.

54 Martis L, Patel M, Giertych J, Mongoven J, Taminne M, Perrier MA, Mendoza O, Goud $\mathrm{N}$, Costigan A, Denjoy N, Verger C, Owen WF Jr: Aseptic peritonitis due to peptidoglycan contamination of pharmacopoeia standard dialysis solution. Lancet 2005;365:588594.
55 Rozenberg R, Magen E, Weissgarten J, Korzets Z: Icodextrin-induced sterile peritonitis: the Israeli experience. Perit Dial Int 2006; 26:402-405.

56 Basile C, De PF, Montanaro A, Giordano R: The impact of relapsing sterile icodextrinassociated peritonitis on peritoneal dialysis outcome. J Nephrol 2003;16:384-386.

57 Perl J, Nessim SJ, Bargman JM: The biocompatibility of neutral $\mathrm{pH}$, low-GDP peritoneal dialysis solutions: benefit at bench, bedside, or both? Kidney Int 2011;79:814-824

58 Schmitt CP, Bakkaloglu SA, Klaus G, Schroder C, Fischbach M: Solutions for peritoneal dialysis in children: recommendations by the European Pediatric Dialysis Working Group. Pediatr Nephrol 2011;26:1137-1147. 


\section{Erratum}

In the article by Achim Jörres [2012;33:153-159], entitled 'Novel Peritoneal Dialysis Solutions - What Are the Clinical Implications?', the following errors should be corrected. In table 1, the units for formaldehyde, 3-DG and 3,4-DGE should be $\mu \mathrm{mol} / \mathrm{l}$. 